\title{
MULHERES NEGRAS, ENSINO SUPERIOR E SUCESSO PROFISSIONAL: ENFRENTANDO O RACISMO
}

\author{
BLACK WOMEN, HIGHER EDUCATION AND PROFESSIONAL \\ SUCCESS: FACING RACISM
}

AlESSANDRA BARBOSA SANTOS

\section{Resumo}

Este trabalho monográfico tem como tema a mulher negra e moradora de periferia e das comunidades do Rio de Janeiro, destinadas historicamente a um status de menoridade social, tanto na educação quanto no mercado de trabalho, mas com a educação tiveram seu futuro reescrito, o trabalho teve como objetivo problematizar o racismo estrutural, machismo e falta de oportunidades presentes na sociedade. A metodologia utilizada foram relatos de vida de mulheres negras e ex moradoras de periferias, pesquisa bibliográfica de diferentes autores, e uma perspectiva do movimento feminista negro. Foi concluído que a mulher negra ainda está em desvantagem de oportunidades na sociedade, entretanto, com a política de cotas e bolsas na universidade, ela tem conseguido conquistar cada vez mais espaços e se inserido no campo profissional que almeja, mesmo que ainda existam muitos paradigmas para serem quebrados.

Palavras-chave: Educação, feminismo, mulher negra

\section{Abstract}

his monographic work has as its theme the black woman who lives in the periphery and in the communities of Rio de Janeiro, historically destined to a status of social minority, both in education and in the labor market, but with education they had their future rewritten, work aimed to problematize structural racism, machismo and lack of opportunities present in society. The methodology used was life reports of black women and former residents of peripheries, bibliographical research by different authors, and a perspective of the black feminist movement. It was concluded that the black woman is still at a disadvantage of opportunities in society, however, with the policy of quotas and

\footnotetext{
a Universidade do Estado do Rio de Janeiro. E-mail: alebsantos14@hotmail.com
} 
scholarships at the university, she has managed to conquer more and more spaces and insert herself in the professional field that she wants, even though there are still many paradigms to be broken.

Keywords: Education, feminism, black woman

\section{INTRODUÇÂO}

A escolha do tema deste trabalho foi inspirada em histórias reais de mulheres negras moradoras e ex-moradoras de comunidade favelizadas do Rio de Janeiro, que conseguiram superar o fator sócio histórico da pobreza e se inseriram no mercado de trabalho através da educação e tornaram-se bemsucedidas, é problemático que mulheres negras sejam a minoria no espaço acadêmico e profissional, a maioria dos negros já iniciam suas vidas precisando lutar muito mais para sua subsistência. Além de precisar enfrentar o racismo estrutural existente na sociedade, a luta da mulher é contra o racismo, machismo e desigualdade. As cotas deram oportunidade para mulheres conquistarem seu espaço, emprego, graduação e independência, a educação transforma a vida de jovens negras quebra paradigmas e dá oportunidades. Todos os direitos civis que a mulher negra usufrui atualmente é resultado da luta das irmãs antepassadas que criaram movimentos sociais porque estavam cansadas de serem excluídas pela sociedade, um desses movimentos criados foi o feminismo negro. Segundo a autora Halina Leal (2020), as mulheres negras não estavam contextualizadas nas dificuldades que o racismo causava, estes problemas se associavam apenas aos homens negros, e as questões de gênero envolviam apenas as mulheres brancas, deixando a mulher negra completamente excluída.

Deste não lugar ou - como afirma Kilomba, a partir de Heidi Safia Mirza (Black British Feminism, 1997) - deste espaço vazio que se sobrepõe às margens da raça e do gênero, denominado de "terceiro espaço", as mulheres negras habitam uma espécie de vácuo de apagamento e de contradição, que se sustenta pela polarização entre mulheres de um lado e negros de outro, com as mulheres negras no meio (Leal, 2020.pg 17)

Como as mulheres negras não estavam incluídas nos problemas sociais, e o movimento feminista as excluía, elas precisaram criar o movimento feminista Rev. Caminhos da Educação: diálogos, culturas e diversidades, Teresina, v. 3, n. 2, p. 143-173, Mai./Ago. 2021 
negro para atender as questões das mulheres negras, esse conceito foi chamado interseccionalidade.

\begin{abstract}
A interseccionalidade é uma ferramenta teórica e metodológica utilizada pelas feministas negras para refletir acerca da inseparabilidade estrutural entre patriarcado, sexismo, e racismo em suas articulações, que implicam em múltiplas situações de opressão sofridas pelas mulheres negras. A intersecção de estruturas racistas e machistas sobre estas mulheres as coloca mais expostas a condições de vulnerabilidade política e social (Leal, 2020.pg 18)
\end{abstract}

No Brasil, também haviam movimentos do feminismo negro na década de 1970, que segundo a autora também apontavam a discriminação e exclusão da mulher negra no movimento feminista brasileiro, segundo as ativistas negras da época, o ativismo das mulheres brancas não dialogava nem atendia as questões do cotidiano da mulher negra. "A epistemologia do movimento feminista negro envolve a valorização das experiências de vida e de visões de mundo das mulheres afrodescendentes" (Leal, 2020.pg 20). Apenas uma mulher negra entende a dor e as necessidades da outra, o movimento negro foi o grito das mulheres para serem ouvidas e entendidas por outras mulheres que compreenderem seu cotidiano, suas vivências, e dificuldades foi uma rede de apoio e força que resultou nos direitos usufruídos hoje, todavia ainda é necessário conquistar muito mais, depois de 50 anos a mulher negra ainda precisa lutar por respeito e igualdade na sociedade, pois por muito tempo ela ficou sem representação, resultando nos problemas sociais de hoje em dia. No entanto, o movimento feminista negro tem se consolidado cada vez mais na sociedade, juntamente com o movimento antirracista e antimachista, e suas reinvindicações estão sendo ouvidas.

\title{
O RACISMO NA SOCIEDADE BRASILEIRA
}

Nos os dias atuais, é possível visualizar os resquícios que a escravidão causou para a comunidade negra, a diferença socioeconômica, falta de oportunidades em discrepância comparada aos brancos e o fantasma social que é o racismo, este que já começa com a normalização do termo raça, que segundo a autora Eucelides, foi um termo criado pelos brancos classificar e Rev. Caminhos da Educação: diálogos, culturas e diversidades, Teresina, v. 3, n. 2, p. 143-173, Mai./Ago. 2021 
inferiorizar os negros, pois a biologia e antropologia física criaram a noção de que a raça humana poderia ser dividida em subespécies como no reino animal. Então, a raça branca seria superior, essa classificação era atribuída também à capacidade intelectual dos negros, que eram considerados incapacitados de aprender, bárbaros e seres não históricos, diferente dos brancos que seriam superiores, mais inteligentes e civilizados. Segundo a teoria darwinista social, essa divisão foi instaurada na sociedade e está presente até atualmente, criando um racismo doutrinário e uma classificação hierárquica na sociedade.

[...] Essa tese esteve focada em um darwinismo social, positivista, que pode ser observado nos escritos de Nina Rodrigues ao estabelecer a sua distinção entre as "raças". Ele elencou as diversas "raças", de modo a distinguir brancos e negros em escalas entre superiores e inferiores, civilizados e bárbaros, histórico e não históricos (IANNI,1966,s/p). Essa construção do pensamento científico hierarquizou as sociedades, as populações humanas e fundamentou o racismo doutrinário. Tal doutrina sobreviveu à criação das ciências sociais, das ciências da cultura e dos significados, respaldando posturas políticas e insanas, de efeitos desastrosos, como aqueles vinculados ao holocausto. (Euclides, 2017, pg.15)

A mestiçagem era abominada e considerada um perigo para a nação brasileira e deveria ser banida da sociedade, o que deveria prevalecer era o embranquecimento da civilização e hierarquização das raças, por esse motivo, a concepção de raça era utilizada para definir a posição os sujeitos e a superioridade dos brancos sustentando o racismo, as características fenótipas dos negros também eram levadas em consideração nessa classificação, os negros eram considerados como inferiores e incapazes. Em 1910, segundo a autora Euclides (2020), houve um movimento para a limpeza das raças, cujo objetivo era de ter unicamente a raça branca no Brasil, estabelecida como raça pura, porque naquela época era inadmissível uma mistura de raças, era considerado até uma doença.

Uma das tentativas de embranquecer a sociedade, foi o incentivo a chegada dos europeus no país, enfraquecendo a ideia de país miscigenado, além da mão de obra que foi dominada pelos europeus que antes era dos 
negros. Os negros no país não tinham direitos as políticas públicas, nem trabalho, moradia ou dignidade, foram deixados à própria sorte excluídos do desenvolvimento do país, além do forte preconceito que enfrentavam instaurado na sociedade. Apenas em 1930 a miscigenação foi entendida como característica do povo brasileiro, após a publicação do livro "Casa Grande e Senzala" do escritor Gilberto Freire, lançado em 1933, a miscigenação deixou de ser uma vergonha e passou a ser considerada como orgulho e encontro cultural.

[...] a mistura étnica ou a miscigenação aparece mais como exaltação do que como degeneração do povo brasileiro, ganhando, assim, uma ideia de equilíbrio e harmonia entre o mito das três "raças". O autor mostrava um Brasil diferente da história dos heróis e grandes homens do passado. Apresentava um novo cenário, no qual, para ele haveria a interação das três "raças": brancos, índios e negros. A mistura étnica e cultural do brasileiro, ao invés de ser percebida como um fator de vergonha, passou a ser percebida como motivo de orgulho: a partir dela é que poderíamos nos pensar como o povo do encontro cultural por excelência, da unidade na diversidade, desenvolvendo uma sociedade única no mundo, precisamente por sua capacidade de articular e unir contrários. (Euclides, 2017, pg.16)

Os negros precisaram enfrentar muitos preconceitos e lutar muito para ter direito a políticas públicas, frequentar espaços, trabalhar, poder usar transportes públicos, votar, estudar, enfim, os direitos básicos que eram concedidos aos brancos e foram proibidos aos negros por muitos anos, devido a tantos anos de negação como cidadão de direitos constitucionais e sem nenhum apoio do governo. No entanto, ainda não foi possível equiparar a dívida social da sociedade com os negros até os dias atuais, sem emprego, estudos, moradia, respeito entre outros, a comunidade precisou encontrar sozinha um meio de subsistência.

\section{TRAGETÓRIA ESCOLAR E ENSINO SUPERIOR, O DIREITO A EDUCAÇÃO}

\section{Ensino básico}

O acesso ao povo negro a escolarização segundo meios oficiais, iniciou aproximadamente durante os séculos XIX e início do séc. XX no período pós escravidão. Durante o período imperial, a proibição do acesso do povo negro à Rev. Caminhos da Educação: diálogos, culturas e diversidades, Teresina, v. 3, n. 2, p. 143-173, Mai./Ago. 2021 
escola era justificada pela crença de que havia uma limitação cognitiva que os impediam de aprender, existia até uma lei (Art.69) que proibia o acesso:

Art. 69. Não serão admitidos á matricula, nem poderão frequentar as escolas:

$\S 1^{\circ}$ Os meninos que padecerem moléstias contagiosas.

$\S 2^{\circ}$ Os que não tiverem sido vacinados.

$\S 3^{\circ}$ Os escravos. (BRASIL,1854, p. 59).

Os motivos da exclusão eram 'higiênicos', referentes à saúde e a eugenia, considerando os escravos como elementos que deveriam ser mantidos apartados da sociedade e da escolarização, como analisa Passos (2012).

A exclusão dos escravos e portadores de doenças contagiosas ao acesso à educação, na análise de Fonseca (2002), pode ser entendida sob dois aspectos: pelo perigo que a instrução, entendida aqui como acesso à leitura e escrita, poderia representar para a estabilidade da sociedade escravista; e, segundo, pela influência negativa que os escravos poderiam exercer nos estabelecimentos de ensino, já que, estes transformariam essas instituições em centros de proliferação de moléstias que poderiam "contaminar" espaço social. Nessa leitura, o contato com os escravizados poderia, também, "contaminar" as crianças com uma cultura primitiva que remontava à África. O que estava em jogo com essas proibições era que os escravos poderiam influenciar com seu comportamento a convivência com os brancos e esses, por conseguinte, poderiam assimilá-los. (PASSOS, 2012, pág.139.)

Em outro decreto, (Art 69) artigo $1^{\circ}$ do Decreto $n^{\circ} 630$ de 17 de setembro de 1854 vemos explicitada a questão de gênero, quando se refere à educação feminina, há a determinação de que além das aulas de gramática e aritmética, as alunas teriam aulas de atividades manuais, como analisam Nascimento e Santos (2018). 
Apesar das mulheres negras não serem explicitamente citadas na lei, elas também foram excluídas. Se a Lei explicita a exclusão dos escravos ao benefício da educação formal, e, com relação ao sexo feminino que se beneficiaria com o aprendizado dos afazeres domésticos, pode-se concluir que, essa Lei estava a serviço de atender as mulheres brancas, e prepará-las para casar. Isso nos faz compreender que as mulheres negras jamais poderiam ser contempladas, pois o seu processo de exclusão já estava legitimamente consolidado no Artigo 69. (NASCIMENTO E SANTOS, pg. 75, 2018).

A demora na integração do povo negro na escola marcou o processo de exclusão das camadas populares da escolarização. Com isso, os reflexos desta exclusão são sentidos na sociedade nos dias atuais, em que os maiores índices de evasão escolar, desemprego, analfabetismo, atingem a população negra, reforçando a associação entre racismo e pobreza, que atinge de maneira mais perversa as mulheres, devido a outro fenômeno persistente, o machismo. Segundo o IBGE de 2017, 48,8\% de mulheres negras tem o ensino fundamental incompleto e de mulheres brancas a taxa é de 33,5\%, já as que possuem ensino médio completo e superior incompleto são $26,6 \%$ das mulheres negras e 33,6\% das mulheres brancas, as que não frequentam escola e são desempregadas a taxa é de $18,7 \%$ das mulheres brancas e $25,9 \%$ das mulheres pretas.

São desigualdades graves e múltiplas, afetando a capacidade de inserção da população negra na sociedade brasileira, em diferentes áreas, comprometendo o projeto de construção de um país democrático e com oportunidades para todos. (PASSOS, 2012, pág. 138.).

No ensino médio, de acordo com Gracyelle Silva Costa (2015), as mulheres negras estão em desvantagem em relação às mulheres e homens brancos na escolarização, segundo dados do IPEA:

No ensino médio, a taxa de distorção idade série atinge $41 \%$ dos jovens negros, contra $26,9 \%$ dos jovens brancos. No entanto, atinge $38,2 \%$ das jovens negras, contra $24,1 \%$ das jovens brancas. (IPEA, 2011, p. 21). 
Ainda assim, de acordo com a autora, as meninas negras têm rendimento escolar melhor do que os meninos negros, pois elas têm menos empecilhos para prosseguir com os estudos, mais foco, interesse, são mais educadas e devido a estes fatores acabam ingressando no ensino superior, ela alega que a taxa de mulheres negras que chegam ao ensino superior é maior do que os homens negros, e que as mulheres pretas têm mais chances de serem bem-sucedidas do que os homens devido ao fator comportamental na vida acadêmica. (COSTA, 2015)

\section{Ensino Superior}

Segundo as autoras Darcele e Carlinda (2016) historicamente as mulheres já são inferiorizadas em relação aos homens por sua anatomia, pela divisão de tarefas e atividades. É evidente que a mulher foi colocada pela sociedade em uma posição hierarquicamente inferior, mesmo que, segundo as autoras, não exista nada que comprove que o corpo da mulher não possa executar as mesmas tarefas do que o homem, então a mulher já nasce sendo discriminada por uma imposição histórica criada pela sociedade. De acordo com as autoras, a mesma imposição da sociedade acontece com negros e brancos, não tem a ver com diferença biológica e sim um conceito construído pela sociedade, em que o negro se encontra hierarquicamente inferior aos brancos em relação a oportunidades e direitos.

Assim, relações de gênero não são simples relações interpessoais entre homens e mulheres. São relações de poder que estão inscritas na "ordem das coisas", isto é, no modo próprio de ser da sociedade, e que hierarquizam posições; são um modo de classificar homens e mulheres com base em representações construídas a partir da sua anatomia (Queiroz e Santos, 2016, pg 76)

Então, a estrutura da sociedade foi baseada nesse conceito de hierarquias raciais e fenótipos, favorecendo um grupo e excluindo outro, segundo as autoras essa classificação sustenta as relações de poder na sociedade brasileira onde existe uma enorme desigualdade social e de oportunidades entre negros e brancos. Na sociedade brasileira, ser mulher e Rev. Caminhos da Educação: diálogos, culturas e diversidades, Teresina, v. 3, n. 2, p. 143-173, Mai./Ago. 2021 
negra é suscetível a dominação e desrespeito de acordo com a hierarquia, pois no Brasil, a raça e gênero são levados em conta para esse tipo de relação.

"Portanto, ser negro e ser mulher são condições que estão inscritas numa ordem hierárquica que tem servido para fomentar a dominação, o desrespeito e a desumanização em todas as esferas da vida daqueles que estão submetidos aos estigmas associados a essas marcas sociais" (Queiroz e Santos, 2016, pg.73)

Segundo um estudo feito em 2015 , pelo IBGE, somente $12,8 \%$ dos negros (pretos e pardos), entre os 18 e 24 anos, são estudantes em instituições de ensino superior no Brasil, o que é considerado muito pouco, visto que a população preta e parda representa $64 \%$ da população brasileira. O que aproximou a entrada do negro e pobre nos cursos superiores foi a implementação de cotas raciais, com o programa de cotas aumentou quatro vezes o número de negros na faculdade.

Entretanto, com todo o avanço que a política de cotas promoveu, segundo o IBGE, esta ainda não conseguiu equalizar com a taxa de alunos brancos graduandos que é de $22 \%$ graduados, isso representa pouco mais do que o dobro dos brancos diplomados no ano 2000, quando o índice era de 9,3\%. Outro fator que possibilitou a ampliação do acesso de jovens negras na escola e faculdade foi a implantação de programas sociais do governo Lula, como o bolsa família que tirou 36 milhões de famílias da pobreza. Com o programa, as jovens não precisam trabalhar para ajudar na renda da família e podem dedicar-se aos seus estudos.

As autoras Darcele e Carlinda fizeram uma pesquisa na Universidade Federal da Bahia no ano 1997, as mulheres ingressadas naquele ano escolhiam curso de menor prestígio social e carreira menos valorizada e que $57 \%$ dos graduandos masculinos ingressaram em cursos das áreas de exatas e tecnológicas. Os cursos de Pedagogia e Enfermagem eram majoritariamente femininos, porque socialmente eram cursos para mulheres e são profissões que exigem mais sensibilidade, na UFBA em 2005 por uma análise feita pelas autoras, a implementação de cotas raciais ampliou o ingresso de alunos negros na universidade e também aumentou a taxa de alunas negras em cursos que Rev. Caminhos da Educação: diálogos, culturas e diversidades, Teresina, v. 3, n. 2, p. 143-173, Mai./Ago. 2021 
são considerados de prestígio social. As autoras fizeram uma pesquisa com estudantes para verificar quais foram suas maiores dificuldades, estas foram o racismo e sexismo, por conta inferiorização racial, desqualificação de gênero e classe impostos socialmente.

\section{AS PROFESSORAS DOUTORAS}

Como citado anteriormente, a história é negacionista em relação aos direitos dos negros, e as mulheres além de sofrerem racismo precisam superar o machismo, na história mulheres negras precisaram lutar muito reivindicando seus direitos e hoje com as políticas de cotas e bolsas de estudo, mulheres negras tem conseguido completar sua educação. Segundo a autora Euclides (2017), professoras negras que adquirem doutorado são mais cobradas no ambiente acadêmico e tem seu conhecimento testado constantemente, e necessitam provar sua capacidade intelectual o tempo todo, para a autora as mulheres negras ainda sofrem o estigma de inferioridade racial e intelectual em relação aos brancos, e ainda estaria inferior ao sexo masculino pela hierarquia criada antigamente.

A célebre discussão já levantada por Munanga (2004), em seu livro, "Negritude, usos e sentidos", sobre o discurso da incapacidade intelectual e moral dos (as) negros (as), encontra-se enraizada na dimensão cultural e relações interpessoais. Assim, as combinações binárias e hierárquicas: branco $\mathrm{x}$ negro, homem $\mathrm{x}$ mulher, desenvolvido $x$ subdesenvolvido, superior $x$ inferior, acabam por delimitar $a$ separação clara do "nós" e do outro. (Euclides, 2017 pg.149)

Ainda segundo a autora, a universidade era um espaço que anteriormente era proibido o ingresso de jovens negras, e por muito tempo essa proibição vigorou, pois, a sociedade acreditava que negras não tinham capacidade intelectual de na academia, assim tornou-se uma prática mesmo que inconsciente testar e duvidar da capacidade das estudantes negras.

Há espaços que é normal entre aspas ser negros então, o espaço da cultura, do esporte é onde se espera que se tenha pessoas negras, mas não na universidade, não no espaço acadêmico, não entre os 
professores, não entre os pesquisadores. (APUD, Luiza Martin, 2015,56).

A autora defende também em sua tese o machismo presente nas universidades, que segundo ela, é um lugar majoritamente masculino e que as professoras doutoras conseguiram quebrar paradigmas para lecionar. A mulher é estereotipada como sexo frágil, desorganizada, e incapaz, assim, quando ela assume um cargo de chefia no meio acadêmico, é cobrada e observada, precisando provar que tem capacidade intelectual de administrar bem 0 programa, coordenação, departamento, qualquer departamento que for de sua responsabilidade. É uma prática também atrapalhar que as mulheres prosperem nos cargos e recebam promoções, pois para o senso comum apenas os homens são sexo forte e organizados e capazes de serem chefes.

Dito isto, mulheres na academia, ou mulheres negras afrontando o espaço acadêmico, são capazes de fomentar novas resistências em jovens mulheres e negras, mediante a corporificação do que lutam, dizem e vivem e isso quer queira quer não, em algum momento é exposto por seus colegas de trabalho como algo estranho, que não deveria estar ali como temática, discussão e/ou problematização no espaço acadêmico. (Euclides, 2017, pg. 153)

As cotas foram um agente fortalecedor para a entrada de mulheres negras na universidade possibilitando o estudo e também as bolsas de pós-graduação. Com isso, o título de doutora possibilitou o reconhecimento, autonomia e liberdade da mulher negra, pois ela pode estudar o assunto que the interessar ganhar bolsas e reivindicar o que lhe é de direito, criar projetos, grupo de estudos entre outros. A entrada dos negros no meio acadêmico foi através de muita luta e desconstrução de estigmas sociais, mas ainda assim, existe muito racismo no meio acadêmico, devido ao "costume" de não reconhecer que um negro tem a mesma capacidade intelectual que um branco.

$\mathrm{O}$ racismo corresponde à negligencia de um conhecimento sobre o povo negro, sua história, maneiras de construir e pensar o mundo para além da cultura eurocêntrica e ocidental. Por outro lado, revela também uma não aceitação da assunção de pesquisadoras negras enquanto 
produtoras e criadoras empiricamente e teoricamente. A "dificuldade" em dar visibilidade às mulheres negras pensando e escrevendo sobre si, que tecem no cotidiano e na academia a construção de um conhecer que se materializa nas experiências vividas e na curiosidade de conhecer-se a si e seus ancestrais, saberes estes tão ausentes nos livros didáticos e nos recursos midiáticos. (EUCLIDES,2017, pg.160)

Apesar de todo e racismo e negligência sofrido pela mulher negra, ela segue resistindo e conquistando espaços, e sua voz não foi silenciada, até na época em que a mulher negra não tinha nenhum direito, lutaram e contrariaram a expectativa a qual a sociedade impôs. Ser mulher e negra na sociedade é ter que lutar contra a opressão, racismo e violência nos espaços em que pisa.

\section{A EDUCAÇÃO COMO FATOR TRANSFOMADOR NA TRAGETÓRIA DE VIDA}

Este capítulo será dedicado a história de quatro mulheres que nasceram e cresceram em comunidades do Rio de Janeiro, e mesmo com muitos fatores não favoráveis conseguiram completar a graduação e se inseriram no mercado de trabalho. Essas mulheres enfrentaram o racismo, pobreza, violência, machismo e conseguiram contrariar as estatísticas impostas pela sociedade, que tenta constantemente silenciar e excluir a mulher negra.

\section{Ana Lucia Barbosa Santos}

I- Infância e família: Fale sobre sua infância, onde você nasceu e cresceu? Qual era a escolaridade e a ocupação dos seus pais?

Meu nome é Ana Lúcia Barbosa Santos, tenho 52 anos e como toda criança da época, não tínhamos acesso as informações em tempo real, como nos dias de hoje através das Redes Sociais. As notícias eram em jornal impresso, rádio ou televisão. Lembro-me também dos programas mais assistidos em família aos domingos, No SBT quase o dia inteiro com Silvio Santos e na Globo, Os Trapalhões e o Fantástico. Gostava dos desenhos, filmes e na hora da novela, além da família reunida, recebíamos duas vizinhas que não tinham televisão "colorida" naquela época. Sou mulher preta, nasci no Hospital Público Rev. Caminhos da Educação: diálogos, culturas e diversidades, Teresina, v. 3, n. 2, p. 143-173, Mai./Ago. 2021 
Hernandes Figueira, criada em Olaria, um bairro periférico da Linha Leopoldina, com mais três irmãos. Sempre estudei em escolas públicas. E, o ensino era de acordo com o aval do regime militar: Ouvir e cantar, em forma, o Hino Nacional, copiar, decorar e quando a diretora da escola entrava em sala de aula ficávamos de pé, em sinal de respeito. Jamais poderíamos questionar um adulto, expor ideias e ou ter opinião própria. Odiava a aula de Educação Moral e Cívica.

Minha referência era a minha mãe que passava o dia inteiro em casa cuidando e educando os filhos. Ela não terminou o $1^{\circ} \mathrm{grau}$ de ensino, era boa em matemática e sempre dizia que "estudar era a porta para a mudança de uma vida melhor", por isso éramos muito cobrados. Meu pai era Militar, na época $3^{\circ}$ Sargento e ele só tinha o $2^{\circ}$ grau de ensino.

II - Escolaridade: Descreva a sua trajetória escolar na educação básica. Quais as principais dificuldades que enfrentou?

Minha trajetória escolar foi sempre com muita luta, sempre dependia de uma explicadora como apoio para português, para ser aprovada para o próximo ano. Meu maior trauma era sempre ver a cara de surpresa dos professores, quando descobriam que eu era irmã do José Raymundo. Eu sempre fui aluna mediana e meu irmão era acima da média, sua média escolar era 9,5. A comparação com ele na Escola me sentia muito inferior. Mas, nunca repeti de ano e no Ginásio sempre fui a Representante de Turma, por votos, que para mim era o máximo, sentia que era referência para negociar, incentivar e organizar. No $2^{\circ} \mathrm{Grau}$, entrei também na escola pública, através de concurso, adorava minha escola. Minha vida mudou radicalmente, passei a tirar notas maiores, podia expressar opiniões, principalmente na aula de História. Não tive dificuldades e passava direto para o próximo ano, não dependia da recuperação escolar. Em toda minha vida escolar nunca fui uma aluna repetente de ano.

III - Ensino Superior: Como foi seu ingresso no ensino superior? 0 que você cursou? 0 que te motivou a escolher este curso? Você fez pósgraduação? Na sua opinião, a educação foi um fator transformador na sua vida? 
A educação é a ferramenta para mudança de vida, sempre acreditei nisso! Fiz concurso para ingressar na Faculdade, lembro-me que minha única opção era noite, para poder trabalhar durante o dia. Não obtive pontuação para cursar Direito nas Universidades Públicas, cursei Direto na Faculdade Gama Filho, na época era uma referência o curso de Direito. Sempre pagava as mensalidades em dia para obter desconto, pois desta forma, ficava viável estudar.

Na verdade, não escolhi fazer Direito, eu queria ser Professora, mas o meu pai me motivou a fazer Direito por ter mais chance em concursos públicos. E o professor não tinha reconhecimento e salário justo. Terminei a faculdade, exerci a profissão na área Trabalhista para uma grande empresa na época, e lá fiquei por 8 anos, até que fui convidada para advogar para uma outra empresa. Minha Pós-Graduação foi em Marketing Estratégico em Varejo e Gestão de Pessoas, sabia verdadeiramente que como Advogada não me realizava ou era feliz! Trabalhei em grandes empresas, desta vez como Gestora de Relacionamento Comercial, com bons salários e verdadeiramente feliz. Tenho planos de fazer Mestrado, mas só depois que terminar meu curso de inglês. $O$ estudo é libertador e possibilita ter uma vida melhor. Sempre falo para minha filha que a mulher que estuda é dona das suas decisões e conquistam as melhores posições. O estudo não tem cor de pele e só depende de você.

IV - Trabalho: Você conseguiu se inserir no mercado de trabalho com facilidade? Você ainda exerce a profissão em que se graduou?

Sim! Fui contratada pela Empresa que eu estagiava. Hoje exerço esporadicamente a profissão, como informei mudei de área.

V - Suas percepções: O que foi mais difícil na sua jornada? Se mudou do local que você cresceu? Você sofreu preconceito por ser negra, mulher ou pobre.

Quanto a preconceitos, posso numerá-los. Sofri preconceito por ser negra, em viagens internacionais, eu sempre era levada para a alfândega, não importava se em grupo ou sozinha. Como mulher preta lembro dos olhares de espanto sempre que frequentava lugares caros ou famosos. Eu e meu esposo quase sempre éramos os únicos negros no local. Sustos dos manobristas Rev. Caminhos da Educação: diálogos, culturas e diversidades, Teresina, v. 3, n. 2, p. 143-173, Mai./Ago. 2021 
quando recebiam nosso carro. Uma realidade muito triste. Uma vez, ao sairmos do Hotel Otton Palace, em 2002, nosso carro deu um problema, era automático e tivemos que pedir um reboque. O motorista ao ver meu marido de Terno, perguntou se eu iria pegar um taxi, acreditando que estava ali como garota de programa. Hoje temos políticas públicas, que proporcionam acesso ao estudo, a busca por igualdade. Nossa luta como mulher preta, está mais representativa e com várias mulheres como referências de sucesso em cargo público, empresarial e área social. Mas, ainda longe do que merecemos estar e muito mais esclarecidas para lutar contra essas desigualdades.

\section{Fernanda Faria Pereira}

I - Infância e família: Fale sobre sua infância, onde você nasceu e cresceu? Qual era a escolaridade e a ocupação dos seus pais?

Fui criada por uma família de 3 mulheres fortes e um avô cego que faleceu quando eu tinha 3 anos, minha mãe, tornou-se mãe aos 15 anos e foi a melhor mãe que poderia ser dentro de toda realidade vivida, tenho o habito de dizer que ela é sobrevivente dentro da sua própria jornada, uma mulher negra, aos 15 anos, criando uma filha em 1994. Tive uma base e uma estrutura familiar potente e feliz, tive como figura paterna meu tio e meu ex padrasto. Nasci no Instituto Fernandes Figueira, fui criada no bairro de Olaria/Zona Norte, aos 9 anos me mudei para Comunidade da Vila Cruzeiro/Penha/Zona Norte. Minha mãe trabalhava como vendedora e em casa de famílias, fazia sua correria referente ao trabalho, minha mãe só teve acesso, tempo e disponibilidade para investir e se dedicar a sua formação depois de adulta, terminou o ensino médio e se formou em Gestão de Recursos Humanos, hoje atua na sua área de trabalho.

\section{II - Escolaridade: Descreva a sua trajetória escolar na educação} básica. Quais as principais dificuldades que enfrentou?

Tive uma vivência "bacana" na escola estudei em escola pública e local do bairro, inclusive tenho relação com meus amigos do ensino fundamental até hoje, durante uma parte do meu processo educacional tive algumas questões 
emocionais referentes a mudanças, minha mãe começou a sofrer violência física dentro de casa e essas questões começaram a implicar no meu desenvolvimento. Comecei a fazer terapia desde muito cedo e esse acompanhamento foi um suporte positivo para me manter interessada na escola. O dia dos pais me marcou muito na escola e por mais que fosse algo conversado em casa era algo que me abalava e me deixava desmotivada.

\section{III - Ensino Superior: Como foi seu ingresso no ensino superior? 0} que você cursou? 0 que te motivou a escolher este curso? Você fez pósgraduação? Na sua opinião, a educação foi um fator transformador na sua vida?

Meu ingresso no ensino superior foi um marco histórico para minha família, uma vitória e conquista coletiva em ser a primeira a entrar no ensino superior, cursei pedagogia, mas queria fazer história ou filosofia, meu desejo aflorou após ficar em recuperação no ensino médio em filosofia e eu precisei de fato me debruçar diante ao estudo e vi o quanto é lindo, forte, estrutural e histórico, é exatamente o que somos como indivíduo e o como refletimos no coletivo o quanto nossas atitudes refletem na sociedade, foi ali que eu entendi que eu fazia parte de uma maioria enquanto população e minoria em cargos altos, foi ali que entendi o racismo estrutural e me reconheci como mulher negra, foi na aula de filosofia que entendi sobre poder aquisitivo, disputa de classe e o quanto representatividade preta é o que nos faltava e falta. Apaixonei-me pela filosofia e decidi que seria a professora preta que eu não tive, com a História foi diferente, um pouco. A história é algo que eu tive acesso enquanto criança, viagens, passeios, a biblioteca do meu avô e um padrasto que gostava de falar sobre isso, no ensino médio no meu último ano tive um professor que me marcou entre suas aulas divertidas, alegres, e que falava de uma história que eu nunca tinha ouvido falar, a escravidão foi me apresentada de forma diferente, ele me contou o quanto os nossos ancestrais lutaram. E ali, reencontrei-me com a história. Minha mãe me encorajou, mas disse que era uma área bem específica e que a pedagogia me daria mais opções de trabalho e após fazer pedagogia e está inserida no mercado, poderia fazer história ou filosofia. Atualmente,, sou pós-graduanda em história e cultura Africana e Afro-Brasileira pelo IPN. 
Como dito o mestre Paulo Freire "A educação não transforma o mundo. Educação muda as pessoas. Pessoas transformam o mundo. " Eu permiti que a Educação me mudasse, aprendi a ouvir, a ler, a perguntar, entendi que o silêncio e o não saber também é um conhecimento, aprendi que as minhas vivências, a minha realidade, a minha história, o meu conhecimento do mundo é tão importante quanto um conteúdo pedagógico e que ele precisa ser valorizado. Através da Educação, tive acesso a lugares de fala, e me movimentar como educadora, mas o movimento mais importante que eu fiz até agora foi incluir minha família nesse processo, minha mãe ingressou no ensino superior após eu entrar, minha prima se formou em um curso técnico após ver minha mãe e eu, ou seja a educação me mudou e eu mudei o meu mundo familiar.

IV - Trabalho: Você conseguiu se inserir no mercado de trabalho com facilidade? Você ainda exerce a profissão em que se graduou?

Iniciei minha trajetória como estagiária em uma escola pequena de Educação Infantil na comunidade onde morava, no primeiro período do curso, foi ali que eu vi o quanto ser professor é um desafio diário e quanto a primeira infância é desvalorizada. Eu tinha muito claro e forte o meu desejo de trabalhar em escolas grandes referenciais, no entanto, não sabia como esse caminho seria feito, pesquisei no Google os melhores colégios do Rio de Janeiro e enviei meu currículo, apenas com a experiência da escola do Bairro e estudante de rede privada, no meu terceiro período da faculdade eu estava como professora auxiliar no Colégio Andrews, e em seguida fui crescendo dentro da área, atualmente sou professora de duas escolas, ainda, na rede particular.

V - Suas percepções: O que foi mais difícil na sua jornada? Se mudou do local que você cresceu? Você sofreu preconceito por ser negra, mulher ou pobre?

Não consigo pontuar um único momento difícil, acredito que eu tenha vivenciado muitos momentos difíceis, o primeiro é o que sistema prepara na educação em relação a defasagem escolar, ou seja, tive que correr atrás de muitas coisas que nunca tinha estudado, comecei a viver dois mundos um mundo de Zona Sul e um mundo de Zona Norte - Favela, esses mundos não 
conversam e são distantes.No entanto, a estrutura e base familiar que eu tive na minha infância e na vida foi fundamental para esse momento, para eu reconhecer que minha história, o meu lugar é lindo, é importante, é forte, e eu sou importante! Sofro o racismo estrutural de uma forma velada, as pessoas pensam como vão me atingir, testam minha inteligência o tempo inteiro, preciso comprovar que eu sei o que estou fazendo e falando, coisa que uma mulher branca não precisa fazer e não é questionada sobre os seus saberes.

\section{Gisele Alessandra de Cerqueira Lopes de Souza}

\section{I- Infância e família: Fale sobre sua infância, onde você nasceu e} cresceu? Qual era a escolaridade e a ocupação dos seus pais?

Então, sou filha de um relacionamento que não deu certo e fui criada e registrada pelo meu padrasto com minha mãe e tenho um irmão. Sou nascida e criada na Vila Cruzeiro, antigamente conhecida como parte Complexo do Alemão, e agora depois da ocupação em 2010, Complexo da Penha. Minha casa era muito simples e no morro. Muitas vezes brincávamos na rua e tínhamos que sair correndo por conta do carro dos bandidos "carro do bicho", que era como chamávamos e ainda por causa dos fogos avisando que a polícia estava chegando e os tiros iriam começar em breve.

Minha mãe concluiu o Ensino Médio Normal (formação de Professores), mas nunca exerceu porque não queria ser Professora, apenas fazia a vontade da minha avó que como mãe era tirana. Já meu padrasto estudou até a antiga $5^{\circ}$ serie, atual $6^{\circ}$ ano. Ele era do interior do Espirito Santo e desde pequeno teve que trabalhar para ajudar em casa. Por isso, alegava não poder estudar. Meu padrasto era caminhoneiro e minha mãe dona de casa.

\section{II - Escolaridade: Descreva a sua trajetória escolar na educação} básica. Quais as principais dificuldades que enfrentou?

Não lembro de dificuldades, pois quando somos crianças não pensamos muito nessas coisas. Para mim, a vida era boa naquela época. Era bom ser criança naquele tempo. O que me motivou a continuar, foi querer ser diferente da minha mãe, da minha família. Também queria mostrar para minha família que 
mesmo sendo a única negra e abandonada aos 8 meses de vida para ser criada por uma mãe solo, que seria capaz de fazer uma faculdade e ter uma vida melhor e até diferente dos demais, e eu consegui, e ainda estou conseguindo, com isso, hoje, sou admirada e respeitada.

III - Ensino Superior: Como foi seu ingresso no ensino superior? 0 que você cursou? 0 que te motivou a escolher este curso? Você fez pósgraduação? Na sua opinião, a educação foi um fator transformador na sua vida?

Foi de um jeito muito inusitado me inscrevi para o vestibular do ISERJ, eu não fiz a primeira prova porque tive que acompanhar a minha filha para fazer a prova dela, como não tinha como estar em dois lugares ao mesmo tempo, desisti. Porém, a prova foi anulada, e como minha filha teria que refazer a prova no mesmo lugar que eu, resolvi fazer a prova e passei, a Pedagogia me esperava, e eu estava muito feliz. Fiquei confusa e com medo, não acreditava que aos 37 anos iria realizar meu sonho, mas aí começou o dilema, porque além dos meus filhos maiores, tinha um pequeno de 3 anos com asma. Ir ou não? Encarar mesmo com as dificuldades ou não? É meu filho? Se ele passar mal? Essas e muitas perguntas vinham, mas eu acabei me organizando e tudo se ajeitou. Fiz matricula e comecei a estudar.

IV - Trabalho: Você conseguiu se inserir no mercado de trabalho com facilidade? Você ainda exerce a profissão em que se graduou?

Não trabalho na área que me graduei. Hoje estou trabalhando na FIRJAN/SESI como agente de Cidadania e em um horário adaptado estou atuando como monitora do Mais Alfabetização em uma escola municipal na Vila Cruzeiro que é onde me sinto realizada.

V - Suas percepções: O que foi mais difícil na sua jornada? Se mudou do local que você cresceu? Você sofreu preconceito por ser negra, mulher ou pobre?

O mais difícil na minha jornada, foi estudar, trabalhar e ser mãe, filha, esposa. Dar conta de muita coisa ao mesmo tempo, tive dias muito difíceis, 
chorei muitas vezes por achar que não conseguiria por conta, por vários motivos, desde a violência que assola a favela até as questões familiares. Mudei da rua que nasci para outra rua próxima, por conta da dificuldade de entrar em casa em dias de operação. Essa rua que resido hoje é uma rua sem acesso ao morro como a de antes, talvez seja por isso que nos dá a falsa impressão de segurança.

Lembro que quando era bem mais nova fui buscar um emprego de promotora de vendas e ouvi da responsável pelo RH que eu não me encaixava, ou melhor, não tinha o perfil para a vaga. Quando olhei em volta, só haviam mulheres brancas com cabelos lisos. Acho que essa foi a primeira vez que realmente senti o que era o racismo. Uma outra situação foi em um hospital quando meu filho chorou sem parar é o segurança veio me perguntar se eu era mãe dele e me pediu o documento dele. Mas sendo sincera, posso garantir que essas situações sempre foram e continuam sendo revertidas em combustível para meu crescimento e tem funcionado há 43 anos.

\section{Iraci Cristina dos Santos Mendonça Santos.}

I- Infância e família: Fale sobre sua infância, onde você nasceu e cresceu? Qual eram a escolaridade e a ocupação dos seus pais?

Minha infância foi no interior, não havia luz, só apenas um fazendeiro chamado Barreto, possuía televisão movida à bateria. Todos os domingos, íamos assistir os trapalhões e o fantástico, existia uma crença de que Barreto virava lobisomen em noite de lua cheia, nesse dia não ia lá nem usava o banheiro, pois ficava do lado de fora da casa. Tomávamos banho de rio, comíamos beiju, brincávamos de cipó, salve a latinha, queimado, foi um período alegre.

II- Escolaridade: Descreva a sua trajetória escolar na educação básica. Quais as principais dificuldades que enfrentou?

Lembro bem meu ingresso na escola aos 7 anos, a escola chamava-se "Educandário São Francisco de Assis" no bairro de Santos Dummont em Aracaju. Como já sabia ler e escrever fui matriculada no segundo ano série 
primária, junto com meu irmão mais velho, estudávamos na mesma sala, nunca tive dificuldade de aprendizagem já meu irmão não conseguia acompanhar. Nesse período, havia a temida sabatina de matemática e a professora sempre colocava meu irmão como minha dupla, eu não gostava, pois tinha que bater no meu irmão, porque ele não conseguia decorar a tabuada. Era utilizada uma régua de madeira redonda. Muitas vezes, fingia não saber para meu irmão me dar uma palmada com a palmatória, para que ele se sentisse bem, porque ele sempre apanhava, a professora incentivava a bater com força. Estudei nesta escola até o oitavo ano, sempre soube que queria ser professora, então minha mãe me matriculou em uma escola normal, minha avó ficou extremamente orgulhosa de ter uma neta professora, porque ela era analfabeta e meu avô desentende de escravos. Ele foi criado na fazenda dos coronéis os servindo em troca de comida junto com minha avó. Minha avó teve doze filhos, maioria tem apenas o ensino médio e alguns analfabetos. Na escola de formação de professores aprendi que para ser uma educadora que transforma vidas, deveria sair do senso comum, questionar me desafiar, ouvir e refletir.

III- Ensino Superior: Como foi seu ingresso no ensino superior? 0 que você cursou? $O$ que te motivou a escolher este curso? Você fez pós-graduação? Na sua opinião, a educação foi um fator transformador na sua vida?

Em 1994, mudei-me para o Rio de Janeiro, vim ser babá de um primo que iria nascer, durante um ano trabalhei como babá na casa das minhas tias, ganhava algumas recompensas como roupas e comida, durante esse período conheci meu marido, que me orientou a procurar um trabalho de carteira assinada, consegui um emprego como caixa de supermercado no grupo Sendas, localizado no Méier, o horário era puxado das 14 às $22 \mathrm{~h}$, mas na prática só acabava quando o último cliente saia. Muitas vezes precisei dormir em uma tia minha, pois não havia mais transporte nesse horário. Mesmo chegando tarde e precisando acordar cedo no trabalho, eu tinha que ajudar minhas tias nas tarefas domésticas. Depois de um tempo, acabei engravidando, meu marido morava no morro do caracol e ganhava pouco como eu, tive que me mudar para a comunidade com pouquíssimos móveis. Seis meses depois engravidei da minha Rev. Caminhos da Educação: diálogos, culturas e diversidades, Teresina, v. 3, n. 2, p. 143-173, Mai./Ago. 2021 
segunda filha, acabei ficando depressiva e tive que pedir licença do emprego, pois se tratava de uma gravidez de risco, pude voltar a trabalhar, mas foi muito difícil com dois bebês.

Nunca gostei de morar no morro devido à violência, certa noite houve um confronto com a polícia e dois tiros atingiram minha casa, o embolso caiu no meu pé perto das crianças que estavam comigo. Nesse dia, entendi que precisava sair daquele local, e conseguimos nos mudar da comunidade, porém meu marido ficou desempregado novamente precisamos nos reinventar, vendemos comida na porta do nosso prédio que morávamos. Em 1998, consegui um emprego em uma creche e fiquei lá por dez anos, meus filhos também estudavam na creche, isso me tranquilizava. Em 2008, fiz concurso para ser professora do município e passei, comecei a ganhar três vezes mais, em 2012, realizei meu sonho de fazer a prova da UERJ, e consegui me classificar em pedagogia. No meu primeiro dia meu coração disparou e senti que ali era meu lugar toda minha vida passou como um filme e senti que aquele momento era meu. Cada período aprendia mais e percebi como a sociedade é desigual e como o preconceito é velado, em vários espaços e como os próprios professores faziam distinção entre as crianças negras e brancas. Mudo isso nos espaços que estou porque a educação mudou totalmente minha vida.

\section{IV- Trabalho: Você conseguiu se inserir no mercado de trabalho com facilidade? Você ainda exerce a profissão em que se graduou?}

Sim, sou especializada em educação infantil pelo centro de referência em educação infantil do Colégio Pedro II, em Realengo. Trabalho na Creche Municipal Tia Ruth Costa dos Santos.

V- Suas percepções: O que foi mais difícil na sua jornada? Se mudou do local que você cresceu? Você sofreu preconceito por ser negra, mulher 
Foram quatro anos muita luta vontade de desistir, as precisava ficas 18 horas fora de casa. Eu precisava concretizar o sonho de ser pedagoga, as adversidades e dificuldades, como a falta de emprego, baixo salário, ou a violência. Criar duas crianças pequenas e trabalhar sem ajuda

Nenhuma dessas mulheres se conhecem, mas suas histórias são semelhantes, todas passaram por momentos de violência em suas vidas, o preconceito estrutural o machismo e os problemas familiares, mulheres de diferentes idades, nasceram em anos diferentes e enfrentaram os mesmos problemas até obter o sucesso acadêmico, percebe-se como a educação abriu portas para essas mulheres tanto profissional como para o autoconhecimento, entenderam o significado da a luta de seus ancestrais e a reivindicar pelo seu lugar de direito nos espaços, elas cresceram e adquiriram emponderamento negro. A educação é um agente transformador, é a única ferramenta capaz de mudar esse ciclo de desigualdade constante na sociedade, todos devem ter acesso a ela, principalmente as mulheres negras, porque a sua trajetória é solitária e vulnerável, ainda mais quando ela nasce em comunidade. A mulher tem muitos deveres, cuidar da casa, dos irmãos, trabalhar, cuidar dos pais, sobreviver à violência do lugar que mora estudar e acaba sendo a última prioridade. Por isso, mulheres negras estão em tanta disparidade social em relação a mulheres brancas, a jornada da mulher negra oriunda de comunidade é extensa e cansativa.

Feministas são formadas, não nascem feministas. Uma pessoa não se torna defensora de políticas feministas simplesmente por ter o privilégio de ter nascido do sexo feminino. Assim como a todas as posições políticas, uma pessoa adere às políticas feministas por escolha e ação. Quando mulheres se organizaram pela primeira vez em grupos para, juntas, conversar sobre questões relacionadas ao sexismo e à dominação masculina, elas foram claras quanto ao fato de que mulheres eram tão socializadas para acreditar em pensamentos e valores sexistas quanto os homens. A diferença está apenas no fato de que os homens se beneficiaram mais do sexismo do que as mulheres e, como consequência, era menos provável que eles 
quisessem abrir mão dos privilégios do patriarcado. Antes que as mulheres pudessem mudar o patriarcado, era necessário mudar a nós mesmas; precisávamos criar consciência". (HOOKS, 2018, pg.23)

Essas mulheres lutaram pela sua liberdade, e contra o patriarcalismo presente nas suas histórias, mesmo que tardio elas conseguiram se libertar e seguir o caminho que escolheram, a luta fim do machismo e patriarcalismo é constante para todas as mulheres negras. A história delas poderia ter sido completamente diferente se elas tivessem desistido de estudar, todas entendem como a educação foi importante em suas vidas, a educação é a chave para o fim da dominação masculina e supremacista branca.

\section{MULHERES NEGRAS NOS ESPAÇOS REPRESENTATIVOS}

O feminismo concedeu o direito de a mulher ter escolhas, de estudar, de trabalhar, de ser mãe e de qual carreira seguir. Com o feminismo as mulheres puderam ter autonomia e poder, a mulher negra tem reivindicado cada vez mais o seu direito de fazer o que quiser e a carreira que quer seguir. Algumas delas são ainda dominadas pelos brancos, mas as mulheres negras têm conseguido se inserir nelas cada vez mais e quebrar paradigmas.

Apesar da baixa representatividade, uma dessas carreiras é na política, segundo uma pesquisa feita PNAD retirada do site Oxfam 2020 mulheres negras compõem apenas $2 \%$ do congresso nacional e menos de $1 \%$ na câmara dos deputados, o que é muito pouco visto que $27 \%$ da população feminina se declaram negra.

O que chamamos de "sub-representação política" das mulheres, atinge as mulheres negras de uma forma crucial. Um exemplo é nosso congresso. Se já temos poucas mulheres representando este espaço, quando fazemos o recorte racial, o número cai drasticamente. Portanto, tanto dentro do espaço parlamentar, quanto dentro dos movimentos sociais, as mulheres negras vêm lutando pela sua afirmação enquanto sujeito político e capaz de estar. À FRENTE dos espaços de poder. O "à frente" vêm ressaltado por perceber que em muitos espaços as Rev. Caminhos da Educação: diálogos, culturas e diversidades, Teresina, v. 3, n. 2, p. 143-173, Mai./Ago. 2021 
mulheres negras, acabam "carregado piano", ou seja, cumprindo funções que dão base aos dirigentes, mas não são tratadas como tal. (GELEDÉS 2013 s/p)

Apenas uma mulher negra entende as necessidades e as vivências da outra, assim podendo representar e sancionar leis que favorecem a outras mulheres negras, uma mulher negra na política significa que uma voz será ouvida e debates sobre o racismo e direito da mulher negra estarão em pauta, o lugar dela lá é significativo para que todas as mulheres negras do Brasil se sintam representadas. No ano de 2020, a primeira mulher negra foi eleita nos Estados Unidos da América, onde ainda existem alguns grupos de supremacia Branca e atos racistas. No Brasil, mulheres negras estão entre as mais votadas também para prefeitas e vereadoras em diversos estados do país, algumas até bateram recorde, como por exemplo, Vivi Reis. Segundo o site Brasil de Fato, ela é mulher negra e amazônica, foi a quinta vereadora mais votada do Pará, em Vitória entre os dez candidatos mais votados, duas são mulheres negras, no Rio de Janeiro, Tainá de Paula teve mais vinte e quatro mil votos e foi a nona mais votada no estado, entre muitas outras.

Este ano (2020), segundo o site, foi o ano em que mais mulheres negras se elegeram em diversos estados do País, a onda do antirracismo e feminismo tem ficado cada vez mais forte e a representatividade em espaços como a política tem crescido, mulheres negras em espaços representativos são extremamente necessárias para o público negro feminino e também um marco importantíssimo de conquista negra, que antes não tinham acessos nem direitos a nada. Além da política, elas também têm se inerido na medicina e direito, carreiras que são socialmente consideradas de "prestigio" e de difícil ingresso, é evidente que a mulher negra tem conquistado cada vez mais o que quer, mesmo que para ela a dificuldade seja maior, e a educação e informação são os fatores proporcionadores dessas conquistas, com a representatividade é possível que um dia a equidade de oportunidades aconteça.

Um dos espaços representativos que tem sido dominado pela presença de mulheres negras é na televisão norte-americana, segundo Silva e Raul (2020), a showronner Shonda Rhymes domina as telas com seus shows, toda Rev. Caminhos da Educação: diálogos, culturas e diversidades, Teresina, v. 3, n. 2, p. 143-173, Mai./Ago. 2021 
noite de quintas-feiras, e faz questão de trazer personagens negras e fortes em posição de prestígio.

Ao destacar a presença na emissora de mulheres negras, mulheres competitivas, mulheres fortes, que são "donas dos corpos e cujas vidas giram em torno do trabalho em vez dos homens, mulheres que são cachorros grandes" (RHIMES, 2019, p. 146), reconhecendo que, se "no salão cheio de mulheres de todas as cores em Hollywood que são executivas e chefes de estúdios e VPs e criadoras de programas e diretoras" (Idem), têm a possibilidade de mudar o jogo é porque existiram mulheres que criaram uma trilha de pegadas que ela percorreu.( Silva e Raul,2020,pg.54)

Segundo as autoras, Shonda também fez questão de quebrar estereótipos, substituindo uma imagem negativa por uma positiva, assim causando uma identificação no telespectador, essa é uma técnica chamada transcodificação.

É na terceira estratégia, a transcodificação, que percebemos o trabalho de Rhimes que "está dentro das complexidades e ambivalências da representação em si e tenta contestar a partir desta esfera" (HALL, 2016, p. 219), se preocupando mais com a forma do que com o conteúdo da representação, aproveitando-se do caráter instável do significado. (Silva e Raul,2020,pg.56)

Shonda quebrou estereótipos e criou uma rede identificação e empoderamento, criando algo novo que muitos executivos não fazem em seus shows, criar personagens negras poderosas, e colocar negros e principalmente mulheres em posição de prestígio "Ao realizar as intervenções radicais a partir de perspectivas silenciadas da representação, Rhimes assume um compromisso ético" (Silva e Raul,2020,pg.56). Shonda foi uma mulher negra que conseguiu crescer e conquistar uma noite em uma emissora com séries apenas de sua autoria em um sistema de supremacia branca. Além de quebrar paradigmas em suas conquistas pessoais, possibilitou que suas telespectadoras negras se identifiquem e entendam que seus problemas cotidianos podem ser o problema de muitas pessoas e que mulheres negras podem sim ser medicas, advogadas 
e assistentes do presidente, Shonda sempre traz críticas sociais em seus shows, assim indiretamente fazendo a luta de grupos serem ouvidos.

\section{CAPÍTULO 3 - PAULO FREIRE E A EDUCAÇÃo PARA OS OPRIMIDOS}

Segundo Paulo Freire (2005), existe algumas classes que podem ser consideradas oprimidas, pois não detém de riquezas e nem da educação de qualidade, para Freire a divisão de classes na sociedade privilegia uns e desfavorece outros, pois a riqueza produzida não é igualmente distribuída, e os oprimidos não desfrutam dessas riquezas, e a riqueza produzida é utilizada na manutenção do sistema de classes, assim uma grande parte da população não usufrui de uma educação de qualidade. Para ele, existem dois tipos de educação uma está a serviço da classe dominante cujo objetivo é manter a dominação dos oprimidos, e a pedagogia do oprimido que sua prática é a liberdade.

Para Freire (2005), o educador deve ser revolucionário e voltado para a humanização dos oprimidos e a educação deve formar indivíduos que assumam o papel de uma pedagogia libertadora. O educador deve ter ética, que significa acabar com a discriminação entre alunos, o preconceito e incentivar os alunos a falar e lutar por seus direitos.

Dentro deste grupo de oprimidos estão os negros, pobres, indígenas e quilombolas que são esquecidos pelo estado e não usufruem de uma educação de qualidade, porque sofrem preconceito por parte da sociedade que não teve uma educação igual proposta pelo autor. Assim, formam-se seres com a mente limitada e com aversão as diferenças, pois na escola não tiveram lugar de fala e nem educação sobre outras culturas e etnias e crenças, e como a prática não muda, o oprimido se torna o opressor.

Freire propõe também que a escola pública deve ser democrática, inclusiva, que ensine os alunos a pensar com um currículo diferenciado e aborde Rev. Caminhos da Educação: diálogos, culturas e diversidades, Teresina, v. 3, n. 2, p. 143-173, Mai./Ago. 2021 
as temáticas étnico-raciais, indígenas, igualdade de gênero, direitos humanos e tolerância religiosa, portanto, Paulo Freire acreditava que a pedagogia poderia ser acolhedora, revolucionária e para todos, ainda não foi atingido esse objetivo nas escolas, no entanto, como o próprio autor citou, é muito difícil o oprimido conseguir se libertar, porém não é impossível. Talvez se as escolas adotassem o método de Freire que propõe uma pedagogia humanizada, o ciclo de violência seria extinto e a escola se tornaria um lugar acolhedor, que entende a jornada massiva das mulheres negras de comunidade e poderiam se adequar a realidade de seus alunos, pois a educação pode ser um lugar de refúgio, e os preconceitos poderiam ser extintos também com essa pedagogia, como no método proposto pelo autor, diferentes culturas além da europeia, que é focada nas escolas, seriam estudadas, seria discutido a cultura africana que também é a história do Brasil, o negro foi o maior responsável pelo crescimento do Brasil, principalmente as mulheres negras que foram obrigadas a ter filhos aqui e criar raízes.

A história do Brasil já acontecia antes da invasão dos europeus, não se ensina nada da cultura indígena, e deveriam ensinar, pois eles eram residentes do país, não existe história dos ex-escravos depois da abolição da escravidão, como eles se estabeleceram na sociedade, como conseguiram sobreviver, não se ensina sobre os reis e rainhas da África, da cultura, biodiversidade, ciência e riqueza, pois lá existe muito mais do que pobreza. O ensino de história nas escolas se limita apenas ao eurocentrismo, devido à educação bancária, a memória coletiva que é construída nos discentes é que o Brasil só tem história porque Cabral chegou, e tudo que é europeu e branco é melhor, como por exemplo, o catolicismo e o protestantismo são religiões europeias e são consideradas "boas" o candomblé que é de matriz africana é considerado "maligno e ruim". O embranquecimento da sociedade é sempre visto como o belo e bom, a escola evitando esses temas corrobora com o racismo, machismo poderia ser desconstruído aos poucos, por isso temas como feminismo seriam abordados, enfim, a pedagogia libertadora é essencial para desconstrução dos preconceitos enraizados. 


\section{CONSIDERAÇÕES FINAIS.}

O feminismo deu as mulheres uma voz que antes era dominada pelo homem branco europeu, dando a mulher negra o lugar que fala e liberdade que Ihe foram negados, segundo a autora o "lugar de fala" significava a opressão e hierarquia de classes raciais, era sobre como uma raça dominava e poderia silenciar a outra.

Lugar de fala" não é somente o poder falar. O conceito não pretende apenas legitimar a expressão de amontoado qualquer de palavras, mas revelar uma hierarquia violenta que subjaz as autorizações, as decisões sobre quem pode e quem não pode falar. Essa hierarquia, por sua vez, é fruto da classificação racial, de gênero e de classe de grupos de pessoas. "Lugar de fala" surge para problematizar e refutar alguns pressupostos da epistemologia dominante, na medida em que possibilita trazer à consciência a existência de estruturas única e essencialmente relacionadas à branquitude no discurso dominante[...] (Leal, 2020.pg 21)

O feminismo foi o responsável pelo empoderamento e justiça social para as mulheres negras, elas entenderam sua posição social política, entenderam seu valor e sua capacidade, se auto afirmando na sociedade, livrando-se das amarras da dominação. Nesse sentido, a superação não envolve somente a libertação das mulheres negras individualmente ou enquanto grupo, mas envolve também a libertação de homens negros, mulheres não negras, comunidade lgbtq + e todas e todos em situações de desigualdade e opressão (Leal, 2020.pg 22). Hoje sabemos que podemos e temos direito de estar onde queremos, e que as tentativas de opressão não irão nos calar, pois agora temos voz ativa e cada vez mais força.

O caminho da mulher negra foi de muita dificuldade e luta, muitas das mulheres negras escravizadas tiveram suas histórias silenciadas, muitas foram mortas nos navios cargueiros, foram arrastadas de sua terra natal e tiveram seus filhos tirados de seus braços, sofreram no açoite, tiveram que criar os filhos dos senhores enquanto viam a infância dos seus filhos ser tirada. O caminho da mulher negra foi trilhado com muita luta e muita resistência e violência, muitas das escravas morreram tentando escapar e sofreram por resistir à dominação Rev. Caminhos da Educação: diálogos, culturas e diversidades, Teresina, v. 3, n. 2, p. 143-173, Mai./Ago. 2021 
branca, essa dominação que não é mais aceita nos dias atuais. Hoje a mulher negra tem lugar de fala, autoestima, acesso à educação, informação, empoderamento, acesso ao mercado de trabalho. Ela pode ser autônoma, atriz, cantora, artista, professora, cientista, médica, advogada, política e o que ela quiser, visto que houve e ainda existe muita luta e movimentos sociais para que a mulher negra possa estar no ambiente profissional que ela desejar, mesmo que ainda exista muita desigualdade na sociedade e ela seja minoria em algum desses espaços, e a dívida de reparação social ainda não tenha sido paga, e ainda tenha muita violência no cotidiano de algumas, ainda assim, mulher negra está conquistando cada vez mais espaços pois hoje ela tem direito a educação, bolsas sociais e de estudo, o que importa é que atualmente não é utopia para uma mulher negra ou periférica ou sem condição socioeconômica faça faculdade. A mulher negra não irá se calar mais diante das desigualdades e opressão, ela agora tem voz e não irá parar de usá-la, tem acesso à educação e não irá parar de estudar.

\section{Referências Bibliográficas}

ANDRADE, Alessandra de; Sá, Juliana Vieira Barbosa; Santos, Rafael dos: $1^{\text {a }}$ ed. Pedagogia da negritude: algumas considerações sobre a obra de Paulo Freire e a questão racial afro-brasileira. Pág 37.

CAMPOS, Marília Lopes de; SANTOS, Ana Cristina dos: Diversidade e transversalidade nas práticas educativas. Rio de Janeiro: NAU, EDUR.2010

COSTA, Gracyelle Silva. Trajetória de escolarização de jovens negras no ensino médio. In UFSC - Florianópolis 2015 In: http://www.anped.org.br/sites/default/files/poster-gt21-4332.pdf Acesso em $11 \mathrm{dez}$ 2018

EUCLIDES, MARIA SIMONE. MULHERES NEGRAS, DOUTORAS , TEÓRICAS E PROFESSORAS UNIVERSITÁRIAS: DESA FIOS E CONQUISTAS' 22/09/2017 254 f. Doutorado em EDUCAÇÃO Instituição de Ensino: UNIVERSIDADE FEDERAL DO CEARÁ, Fortaleza Biblioteca Depositária: UNIVERSIDADE FEDERAL DO CEARÁ/CENTRO DE HUMANIDADES 
FREIRE, Paulo: Pedagogia do Oprimido, $17^{\text {a }}$ ed. Rio de Janeiro, Paz e Terra, 1987.

em:

http://www.dhnet.org.br/direitos/militantes/paulofreire/paulo freire pedagogia do opri $\underline{\text { mido.pdf }}$

HOOKS, Bell. O feminismo é para todo mundo [recurso eletrônico]: políticas arrebatadoras / bell hooks; tradução Ana Luiza Libânio. - 1. ed. - Rio de Janeiro: Rosa dos Tempos, 2018. Recurso digital. Acesso em 14/09/2020

LAPSKY, Igor. Introdução aos Estudos Históricos. Universidade de Pernambuco - UPE. Impresso no Brasil - Tiragem 180 exemplares. 2017 pág 13.

$\begin{array}{cccccccc}\text { Passos, } & \text { Joana } & \text { Célia } & \text { dos: As desigualdades } & \text { na } & \text { escolarização da } \\ \text { população } & \text { negra } & \text { e } & \text { a } & \text { Educação } & \text { de } & \text { Jovens } & \text { e }\end{array}$

Adultos. In: Revista EJA em debate, Florianópolis, vol. 1, n. 1. nov. 2012. Disponível em: https://periodicos.ifsc.edu.br/index.php/EJA/article/view/998/pdf f acesso em : $11 / 03 / 2019$

QUEROZ, Daciele Mascarenhas;SANTOS, Carlinda Moreira dos. AS MULHERES NEGRAS BRASILEIRAS E O ACESSO À EDUCAÇÃO SUPERIOR' jan./abr. 2016 f. Revista da FAEEBA - Educação e Contemporaneidade, Salvador, v. 25 , n. 45 , p. $71-8$

Santos, Carlinda Moreira dos. A Mulher Negra no Ensino Superior: Trajetórias e Desafios' 01/10/2012 215 f. Mestrado em EDUCAÇÃO E CONTEMPORANEIDADE Instituição de Ensino: UNIVERSIDADE DO ESTADO DA BAHIA, Salvador Biblioteca Depositária: Biblioteca Central da Universidade do Estado da Bahia

Santos, João Paulo Lopes dos; Moreira Núbia Regina. MULHER NEGRA E EDUCAÇÃO SUPERIOR: IMPASSES HISTÓRICOS E ATUAIS. 26 a 29 de setembro. XII COLÓQUIO NACIONAL E V COLÓQUIO INTERNACIONAL DO MUSEU PEDAGÓGICO: Museu pedagógico. Disponível em: http://anais.uesb.br/index.php/cmp/article/viewFile/6935/6735

Site IBGE: Estatísticas Sociais: Estatísticas de gênero: responsabilidade por afazeres afeta inserção das mulheres no mercado de trabalho. Disponível em: https://agenciadenoticias.ibge.gov.br/agencia-sala-de-imprensa/2013-agencia-de- 
noticias/releases/20232-estatisticas-de-genero-responsabilidade-por-afazeres-afetainsercao-das-mulheres-no-mercado-de-trabalho

SITE OXFAM: A participação de mulheres negras na política importa! Entenda os motivos. Disponível em: https://www.oxfam.org.br/blog/mulheres-negras-na-politica/ acesso em 17/11/2020 às $21: 20$

Site Geledés: Mulheres Negras e o Poder: Nós também podemos. Disponível em: https://www.geledes.org.br/mulheres-negras-e-o-poder-nos-tambempodemos/?gclid=Cj0KCQiAhs79BRD0ARIsAC6XpaWICu1tVgF2PJ Bjm9ILQKdbqAiM ZrZ3L9S Derg5pVI83DdUs -OYaAoBfEALw wcB

RECEBIDO: 01/04/2021

APROVADO: 01/05/2021 